\title{
Prosthodontic rehabilitation after traumatic anterior teeth and anodontia of mandibular right second premolar: a case report
}

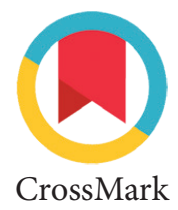

\author{
Ike D. Habar ${ }^{1}$, Muchammad Ardiansyah ${ }^{2 *}$, Ervina S. Surya ${ }^{1}$, Richard Tetelepta $^{3}$, \\ Maqfirah Amiruddin', Meriyam Muchtar ${ }^{4}$
}

Abstract

Objective: The success of rehabilitation patients depends on strategic treatment planning and choice of most suitable treatment modality. In this case, a 20 years male, reported both the maxillary central incisors were found to be fractured, $1 / 3$ and 2/3 apical of teeth. In mandible condition, second right premolar is anodontia.

Methods: This case report describes technique in restoring an uncomplicated fractured maxillary anterior teeth in a young patient with laminate veneer porcelain restoration and post fiber post with core build-up resin followed by using of porcelain crown for traumatic

tooth and single implant for treatment second right premolar of mandible.

Results: Porcelain veneers is a conservative method of restoring the appearance of discolored, pitted teeth, and teeth with diastema that provide extremely good esthetic results. Post and post-core systems are used to restore extensively damaged teeth. Implants are considered as a first treatment option to replace missing teeth due to the considerable advantages over the other available options. Conclusion: The ultimate goal of this case treatment is to restore natural esthetics, function, long term health and patient comfort.

Keywords: Prosthodontic rehabilitation, Porcelain veneers, Porcelain crown, Implant

Cite this Article: Habar ID, Ardiansyah M, Surya ES, Tetelepta R, Amiruddin M, Muchtar M. 2018. Prosthodontic rehabilitation after traumatic anterior teeth and anodontia of mandibular right second premolar: a case report. Journal of Dentomaxillofacial Science 3(2): 129-131. D0I: 10.15562/jdmfs.v3i2.730

${ }^{1}$ Department of Prosthodontic, Faculty of Dentistry, Hasanuddin University, Makassar, Indonesia

${ }^{2}$ Department of Prosthodontic, Dentamedica Care Center \& TJ Dent Medical Specialist, Makassar, Indonesia

${ }^{3}$ Department of Prosthodontic, Naval Dental Hospital Ladokgi Yos Sudarso, Makassar, Indonesia

${ }^{4}$ Department of Prosthodontic, Health Center, East Luwu, Indonesia

*Corresponding to:

Muchammad Ardiansyah, Department of Prosthodontic, Faculty of Dentistry, Hasanuddin University, Makassar, Indonesia ardiansyahmuchammad@gmail.com

Received: 19 March 2018

Revised: 26 March 2018

Accepted: 9 July 2018

Available Online 1 August 2018

\section{Introduction}

Last decade the development of dental care is not just to treat a disease but at the same time caring for aesthetic purposes. Therefore the selection of the current restoration in addition to meeting the criteria for restore functions and also aesthetic. The success of rehabilitation patients depends on strategic treatment planning and choice of most suitable treatment modality. Management of patient's with anterior tooth fracture provides great challenge to the clinicians both from a functional and an esthetic perceptive. Treatment objectives may vary depending on the age, socio-economic status of the patient and intraoral status at the time of treatment planning. There are various treatment modalities for restoration of fractured teeth like composite restoration, fixed prosthesis, reattachment of the fracture fragment (if available) followed by post and core supported restorations. ${ }^{1}$

Endodontically treated teeth are widely considered to be more susceptible to fracture than vital teeth. Obturation procedures and post placement have been a main cause of vertical root fracture. Endodontically treated teeth are widely considered to be more susceptible to fracture than vital teeth. Obturation procedures and post placement have been a main cause of vertical root fracture. Posts and cores can be custom-made or prefabricated. Modern dentistry has seen the development of many new materials and techniques. Two major developments in recent times are dentine bonding and stronger all-ceramic crown. Dentists should also keep basic biomechanical principles in mind and be wary of information put out by companies with a vested commercial influence. ${ }^{2,3}$

Advances in the technology of bonding porcelain to enamel created the possibility of porcelain veneers as an alternative to the use of full crowns for the treatment of many clinical conditions, such as treatment of diastema, misaligned teeth, worn dentition, chipped teeth, and excessively discolored teeth. Porcelain veneers and crown all porcelain is a conservative method of restoring the appearance of discolored, pitted teeth, and teeth with diastema that provides extremely good esthetic results and alternative to more extensive restorative procedures. ${ }^{4}$

Replacement of anodontia with dental implants also one of the most appropriate choice since it could restore the function also provides aesthetic results and patient comfort. It has become one of the most important needs for patients attending clinics to restore esthetics and/or function. Many treatment modalities are available for replacing a single missing tooth; removable partial denture, fixed partial denture or dental implant. Each modality is a possible treatment option and has its own advantages and disadvantages. ${ }^{5}$ 
This case report aesthetic rehabilitation and describes technique in restoring an uncomplicated fractured maxillary anterior teeth and single implant for treatment anodontia of mandible.

\section{Case Report}

A 20 years male, presented $1 / 3$ apical fracture of teeth 11 and $212 / 3$ apical fracture. In the lower jaw 44 is anodontia, and has made extraction of 33 and 43 about 1 year ago due to impaction. Patient
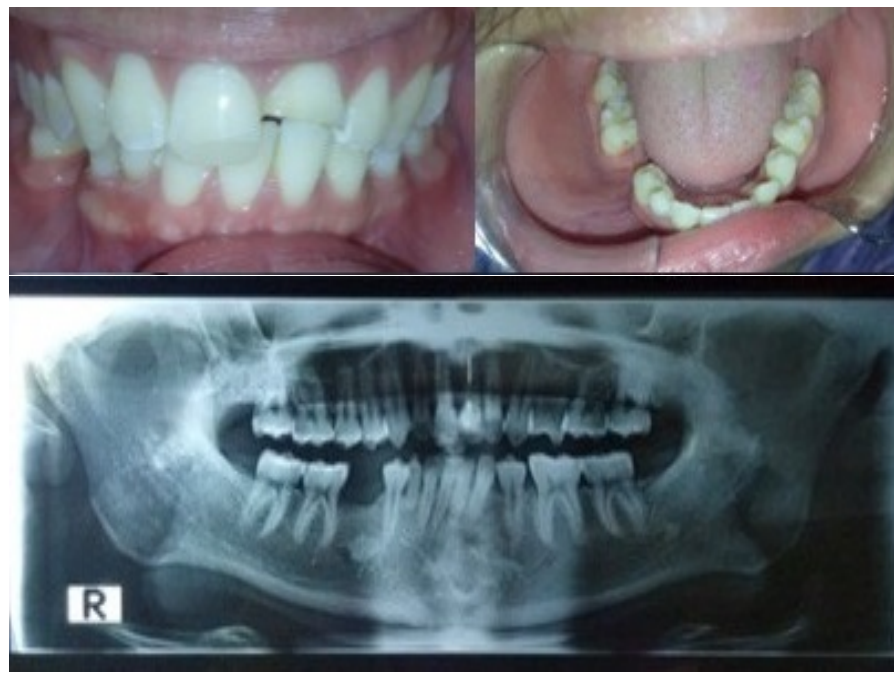

Figure 1 Initiate intraoral and panoramic radiograph

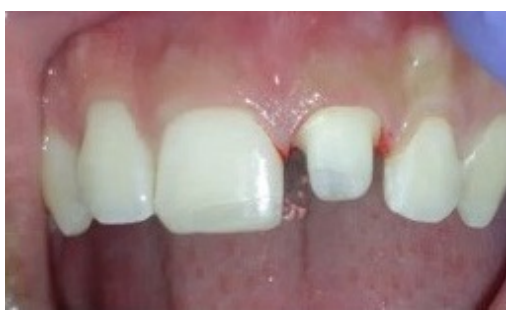

A

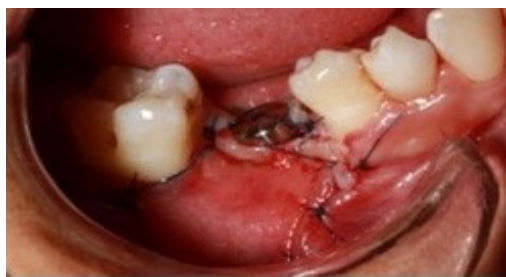

$\mathrm{C}$

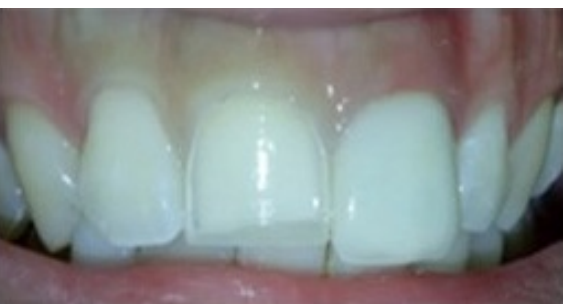

B

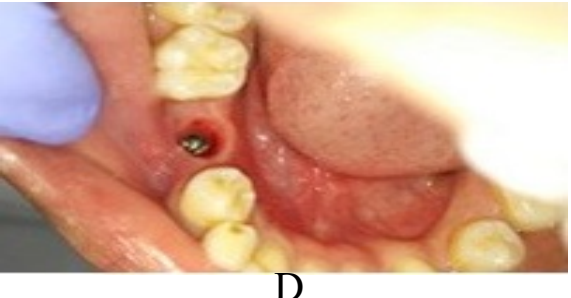

D
Figure 2 A. Fibre post with resin core, B. Preparation for veener, C. Primary closure, D. Gingiva healing

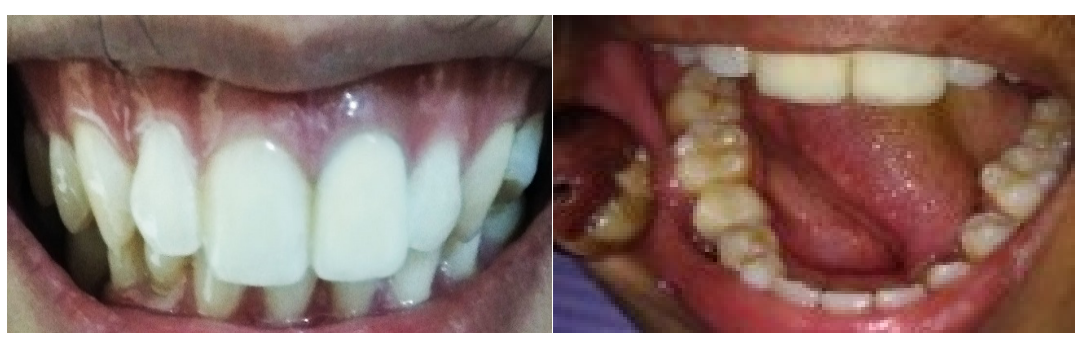

was carefully evaluated medically, clinically, and radiographically to assess current health status and to identify any pathologies that required preliminary treatment figure 1. A diagnostic workup was performed to evaluate the volume and location of available bone, esthetic and functional needs of the case, and desires of the patient. Single implant was installed on 44 with bone grafting. Laminate veneer treatment with overlap incisal prep was carried out on 11 and fibre post with resin core build-up followed by crown all porcelain on tooth 21 figure 2A-D.

\section{Implant Analysis using CBCT}

CBCT analysis of a patient referred for dental implant treatment planning of an edentulous space in the posterior right mandible. The analysis using CBCT acquired, mesiodistal witdh: $10.1 \mathrm{~mm}$, buccallingual witdh on region $45: 4.1 \mathrm{~mm}$, bone height to foramen mentale on region $45: 9.9 \mathrm{~mm}$

\section{Prosthetic Procedure}

After healing period, about 8 weeks, we took an impression for making the upper structure. We did closed method impression technique by using transfer impression coping. For abutment we used $\mathrm{Np}$-cast abutment and screw retained crown was performed. Final restoration treatment shows good result and patient satisfy with the treatment figure 3.

\section{Surgical Procedure}

On the first step of the procedure, we took anatomy impressions of maxilla and mandibular. After that, we analyze bone witdh and height using CBCT Imaging and made a surgical guide template for guidance for marking spot. Second step, we did the surgical procedures, desinfected the surgical area, then anesthetized on mucobuccal and lingual were delivered. A crestal incision was made using blade no.15C with extended vertical incision (trapezium flap design), flap was elevated with periosteal elevator. After that, we used the lance drill on region 45 to marking spot, next used twist drill $\phi 2.2 \times 8.5 \mathrm{~mm}$ then we examined with guide (parallel) pin. We used taper drill $\phi 3.5 \mathrm{~mm}$ and final drill was $\phi 4.0 \times 8.5 \mathrm{~mm}$. Implant was placed at the position of tooth. We used Osstem TSIII $\phi 4.0 \times 8.5 \mathrm{~mm}$, then healing abutment was placed. We added some bone graft material and membrane on buccal side and then primary closure with interrupted sutured. Instructions post operative were given to patient and prescribed antibiotics, analgesics, and anti-inflammations. After 1 weeks panoramic radiographic post surgical was taken.

Figure 3 Final restoration veener and crown 


\section{Discussion}

Porcelain laminate veneer and fibre post with resin core build up followed by crown all porcelain are the most conservative and esthetic restoration that can be used for enhancing esthetics and has been shown to be a valid management option especially in the anterior aesthetic zone. Use of fibre post and resin core reduces chances of fracture as less tooth preparation is required.

Various preparation depths and 3 types of preparation forms have been described for porcelain laminate veneers, namely, window, overlapped and feathered preparations. To date, there is no consensus as to which preparation type is more resistant to fracture. Therefore, the least invasive preparation with maximal preservation of enamel is advisable. ${ }^{6,7}$

Veneers is considered to be a more conservative treatment approach than full crowns because preparation of the teeth for veneers requires less tooth reduction than full crown preparations. Porcelain veneers are very suitable for young adults who have large pulp chambers and pulp horns close to the teeth enamel surface. ${ }^{4}$

Crowns on tooth preparations with margins beyond the CEJ and with adequate resistance form should be cemented in place with an RMGI cement rather than a resin cement. Crowns on tooth preparations with margins beyond the CEJ and with inadequate resistance form should be cemented in place with resin cements. Crowns on tooth preparation with equigingival margins in enamel and good underlying substrate colour should be made from a translucent, glass based ceramic system. ${ }^{3}$ By replacing single missing tooth for looking and functioning like a natural tooth, a dental implant replaces a single tooth without sacrificing the health of neighboring teeth. In the long term, a single implant can be more esthetic and easier to keep clean than a bridge. But in this case, for receiving esthetic result on buccal plate was difficult due to large defect and also need to use titanium mesh membrane to maintaine bone volume.

In clinical decision making, dentists routinely choose between alternative treatments such as crown vs amalgam/composite buildup, root canal treatment vs extraction fixed bridge vs removable partial denture and periodontal treatment vs extraction. The level of education and patients awareness towards different treatment modalities to replace single missing tooth have significant effect on the treatment choice. All treatment options offered advantages but also some disadvantages. The FPD restores three units; the single crown on an implant will just replace one tooth. With the implant reconstruction, no abutment teeth have to be prepared avoiding the risk for addi tional endhodontic treatment, discomfort because of hypersensitivity, difficult access for plaque control, etc. $^{5}$

\section{Conclusion}

By performed of laminate veneer restoration and fiber post all porcelain crown in anterior teeth maxilla and single implant in mandibular patient's appearance can be improved aesthetically and restore stomatognasi function.

\section{Acknowledgment}

I would like to express my deepest appreciation to all those who provided me the possibility to complete this report. A special gratitude I give to our patient Akira for his patience in during the treatment and my senior Vina for contribution in stimulating suggestions, helped me in writing this report.

\section{Conflict of Interest}

The authors report no conflict of interest.

\section{References}

1. Rajavardhan K, Sai-Sankar AJ, Ahmed-Shaik T, et al. A novel technique in restoring fractured anterior teeth. J Clin Diagnostic Res 2014;8: 244-245.

2. Moosavi H, Afshari S, Manari F. Fracture resistance of endodontically treated teeth with different direct corono-radicular restoration methods. J Clin Exp Dent 2017;9: e454-459.

3. Mizrahi B. The anterior all-ceramic crown: a rationale for the choice of ceramic and cement. Br Dent J 2008;205: 251-255.

4. Kamble VD, Parkhedkar RD. Esthetic rehabilitation of discolored anterior teeth with porcelain veneers. Contemp Clin Dent 2013;4: 124-126.

5. Al-Quran FA, Al-Ghalayini RF, Al-Zu'bi BN. Single-tooth replacement: factors affecting different prosthetic treatment modalities. BMC Oral Health 2011;11: 34.

6. Re D, Augusti G, Amato M, et al. Esthetic rehabilitation of anterior teeth with laminates composite veneers. Case Rep Dent 2014;2014: 9.

7. Cialy J, Thalib B, Dharmautama M, et al. . Preventive and conservative prosthodontic treatment using overdenture and Richmond crown. J Dentomaxillofac Sci 2016;1: 193-195.

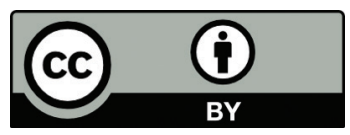

This work is licensed under a Creative Commons Attribution 